Check for updates

Cite this: RSC Adv., 2017, 7, 25191

Received 22nd March 2017

Accepted 17th April 2017

DOI: $10.1039 / c 7 r a 03379 f$

rsc.li/rsc-advances

\section{Polyaniline-modified nanocellulose prepared from Semantan bamboo by chemical polymerization: preparation and characterization}

\author{
Rawaida Liyana Razalli, ${ }^{a}$ Mahnaz M. Abdi, (D) *ab Paridah M. Tahir, ${ }^{a}$ Amin Moradbak, ${ }^{a}$ \\ Yusran Sulaiman iD ${ }^{b}$ and Lee Yook Heng ${ }^{c}$
}

\begin{abstract}
Crystalline nanocellulose was prepared from Semantan bamboo (Gigantochloa scortechinii) via acid hydrolysis and was used to synthesize a nanocomposite of polyaniline/crystalline nanocellulose (PANi/CNC) via in situ oxidative polymerization of aniline in the presence of crystalline nanocellulose. The electrochemical properties of the nanocomposite were studied using a modified PANi/CNC electrode via cyclic voltammetry, and higher current response was observed for the PANi/CNC-modified electrode compared to that for the modified electrode with PANi. The results obtained from EIS displayed lower value of $R_{\mathrm{ct}}$ for the PANi/CNCmodified electrode, indicating that the incorporation of CNC into the PANi structure could enhance the electron transfer rate. The characteristic peaks of PANi and CNC were observed in the FTIR spectra of the nanocomposite, indicating the incorporation of CNC inside the nanocomposite structure. Moreover, in the XRD diffractogram, lower crystallinity was observed at the 2 theta values of 22.6 and 16.1 for PANi/CNC compared to that for pure CNC. The FESEM images showed high porosity of the nanostructure with no phase separation, revealing the homogenous polymerization of the monomer on the surface of the crystalline cellulose. Aggregation of PANi particles was observed with the increasing aniline concentration.
\end{abstract}

\section{Introduction}

Conductive polymers have unique electrical and thermophysical properties and possess interesting features that have enabled their use in a variety of commercial applications. ${ }^{1}$ Polyaniline (PANi) is one of the well-known conducting polymers that has been widely used in numerous applications including supercapacitors, ${ }^{2-4}$ batteries,${ }^{5}$ chemical and biological sensors, ${ }^{6,7}$ electrical conductors, ${ }^{8}$ and in anti-static coatings. ${ }^{9}$ However, PANi has some disadvantages: for example, it has low dispersibility and solubility in most solvents and low electron transfer rates and conductivity in solutions with a higher $\mathrm{pH}$, which have limited its performance in biosensors and electrical devices. ${ }^{\mathbf{1 0 , 1 1}}$

During recent years, some research has been carried out to address these limitations, in particular, the preparation of PANibased nanocomposites by the addition of nanoparticles, inorganic materials or biopolymers such as nanocellulose. A ternary manganese ferrite/graphene/polyaniline (MGP) composite reported by Xiong et al. ${ }^{12}$ was synthesized through a facile two-step

${ }^{a}$ Institute of Tropical Forestry and Forest Products, Universiti Putra Malaysia, 43400 Serdang, Malaysia

${ }^{b}$ Departments of Chemistry, Faculty of Science, Universiti Putra Malaysia, 43400 Serdang, Selangor, Malaysia.E-mail: mahnaz@upm.edu.my

${ }^{c}$ Faculty of Science and Technology, National University of Malaysia, 43600 Bangi, Selangor, Malaysia strategy, and an improvement in the electrochemical capacitance and cycling stability was observed. Qi et al. ${ }^{13}$ attempted to improve the performance of PANi by preparing PANi/non-woven fabrics using an in situ polymerization method. The porous structure of the non-woven fabrics could enhance the electron transfer and sensitivity of the gas sensor. Liu et $a .^{\mathbf{1 4}}$ fabricated a flexible and electrically conductive nanocellulose-based polyaniline composite film. They reported that the composite film with a thickness of $50 \mu \mathrm{m}$ could be bent up to 180 degrees without breaking. The synergistic effect of the high surface area of the nanocellulose and the good electronic conductivity of the conducting polymer made the nanocomposite compatible for applications such as in electrochemically controlled ionexchange, ultrafast all-polymer-based batteries, and sensors. ${ }^{15}$ Nystrom et $a .^{15}$ reported the preparation of an ultrafast high performance paper-based battery using a cellulose-PPy composite. The lightweight and flexible composite cellulosePPy had a specific surface area of $80 \mathrm{~m}^{2} \mathrm{~g}^{-1}$. For application in batteries, the cell could be charged using currents as high as 600 $\mathrm{mA} \mathrm{cm}{ }^{-2}$ with only a $6 \%$ loss in capacity in over 100 subsequent charge and discharge cycles.

In this study, the polymerization of aniline in the presence of nanocellulose to improve the physical and electrochemical properties of PANi is reported. Hydroxyl groups that cover the surface of cellulose allow it to react well with a variety of materials including conducting polymers. ${ }^{14,16,17}$ To enhance the performance of the polymer for biosensor applications, 
crystalline nanocellulose (CNC) was introduced into the polymer structure to provide a larger active surface area and higher specific strength. ${ }^{17} \mathrm{CNC}$ is a derivative of cellulose that has been classified as a new class of nanomaterials, and it is formed via an acid hydrolysis process that creates rigid rod-like crystals with diameters ranging from 10 to 20 nanometers and lengths of a few hundred nanometers. ${ }^{18,19}$ In this study, the nanocellulose was prepared from Semantan bamboo (Gigantochloa scortechinii) by acid hydrolysis. To the best of our knowledge, this is the first report on the preparation of CNC from Semantan bamboo for biosensor applications.

For biosensor applications, it is essential for the composite to be able to perform under neutral conditions as most enzymes work well in neutral pH. As is known, PANi generates high conductivity only in acidic media; however, PANi composites have been used in neutral media as biosensors in most cited studies. Ghosh et al. $^{20}$ stated that a certain amount of cellulose could produce enough net negative charges on the PANi cellulose composite due to the ionization of the acidic moieties such as carboxyl, sulphonic acid, or hydroxyl groups on the surface of the cellulose. To balance this excess charge, the composite undergoes protonation, and the proton concentration inside the composite increases compared to that of the external solution. Thus, PANi in composites is protonated and hence able to conduct even in a neutral solution.

The nanocomposite of PANi and CNC synergistically combines the electronic properties of the conjugated polymer with the structural advantages of cellulose to be useful in different applications including as biosensors. In this research, the nanocellulose was prepared from Semantan bamboo by acid hydrolysis, and it was expected that CNCs with a high active surface area and aspect ratio with improved electron transfer in nanocomposites would be formed.

\section{Experimental details}

\subsection{Materials}

Aniline (Ani), ammonium persulfate (APS), hydrochloric acid $(\mathrm{HCl})$, and all analytical grade reagents were purchased from R\&M Chemical. Phosphate buffer solution (PBS) was purchased from Systerm. Aniline monomer was doubly distilled before use and deionized water (DIW) was used throughout the synthetic work. Screen-printed carbon electrode (SPE) was purchased from DropSens.

\subsection{Crystalline nanocellulose preparation from Semantan bamboo pulp}

Cellulose nanocrystal (CNC) was prepared via sulfuric acid hydrolysis of bleached Semantan bamboo pulp. The bleached pulp was hydrolysed by $64 \%$ sulfuric acid at $45^{\circ} \mathrm{C}$ for 45 minutes under dynamic stirring at $400 \mathrm{rpm}$. The $\mathrm{v} / \mathrm{v}$ ratio of acid-tocellulose was $1.00: 8.25$. After acid hydrolysis, the suspension was placed in an ice bath to stop the hydrolysis reaction. The final $\mathrm{pH}$ of the suspension was adjusted to about 6 by adding $5 \%$ sodium bicarbonate and distilled water. The suspension was centrifuged at $6000 \mathrm{rpm}$ for 30 minutes and washed six times to remove the surplus sulfuric acid. To obtain the CNC in powder form, the suspension was dried using a vacuum freeze dryer.

\subsection{Preparation of the nanocomposite}

Various amounts of monomer (aniline) were mixed with $1 \mathrm{M}$ hydrochloric acid $(\mathrm{HCl})$ in an ice bath. $\mathrm{CNC}$ was suspended in DIW and was moderately stirred until the solution reached homogeneity. Both the solutions of monomer and CNC were mixed and stirred at $0-5{ }^{\circ} \mathrm{C}$ for 20 minutes. The aniline solutions were prepared at the concentrations ranging from 0.12 to 0.20 molar, and the mass ratio of Ani/CNC was chosen in the range from 1 to 0 ( $0 \% \mathrm{CNC}$ refers as pure PANi). The solution of APS was added dropwise to the mixture in which the molar ratio of APS and aniline was always maintained at $1: 1$. The mixture was kept under stirring for 45 minutes and was allowed to rest at room temperature for 18 hours. The green emeraldine polyaniline precipitate was filtered and washed with distilled water at least 3 times by centrifugation till the supernatant become clear at $4500 \mathrm{rpm}$. The precipitate was dried in the oven at $60{ }^{\circ} \mathrm{C}$ for 6 hours. For reference, pure PANi powder was synthesized using the same procedure in the absence of CNC.

\subsection{Preparation of the modified electrode}

Herein, $1 \mathrm{mg}$ powder of PANi/CNC nanocomposite in $2 \mathrm{ml}$ DIW was sonicated for 30 minutes. The suspensions were dropcast on the screen printed electrode (SPEs) and it was dried at room temperature.

\subsection{Characterization}

The electrochemical measurements were conducted using a potentiostat Autolab 204 from Metrohm Autolab connected to a PC and controlled by Autolab Nova software version 1.11. The $\mathrm{CV}$ measurements were carried out over a potential range from $-1.5 \mathrm{~V}$ to $1.5 \mathrm{~V}$ with the scan rate of $100 \mathrm{mV} \mathrm{s}^{-1}$. The EIS measurement was performed over a frequency range from $0.1 \mathrm{~Hz}$ to $100 \mathrm{kHz}$ at an AC amplitude of $5 \mathrm{mV}$. FTIR analysis was performed on the samples using the PerkinElmer Spectrum 100FT-IR spectrometer in the transmittance mode over a range of 4000-400 $\mathrm{cm}^{-1}$. FESEM analysis was carried out using a JEOL JSM-7600F field emission scanning electron microscope, a secondary detector, 3.0 probe size, and $20 \mathrm{kV}$ acceleration voltage. The samples were mounted on the aluminium stub followed by coating a thin layer of gold to avoid charging. TEM was conducted using a Hitachi H-7100 TEM. The TGA analysis was carried out using the TGA/SDTA 851 (Mettler Toledo) thermogravimetric analyser at a constant heating rate. XRD analysis was carried out using a PANanalytical EMPYREAN diffractometer at $4.0 \mathrm{~kW}$ power supply, $100 \mathrm{~mA}$ current flow, and $60 \mathrm{kV}$ operation voltage.

\section{Results and discussion}

\subsection{Electrochemical study}

The electrochemical properties of the nanocomposite were studied using cyclic voltammetry $(\mathrm{CV})$, and the results are shown in Fig. 1. Fig. 1A compares the cyclic voltammograms of 

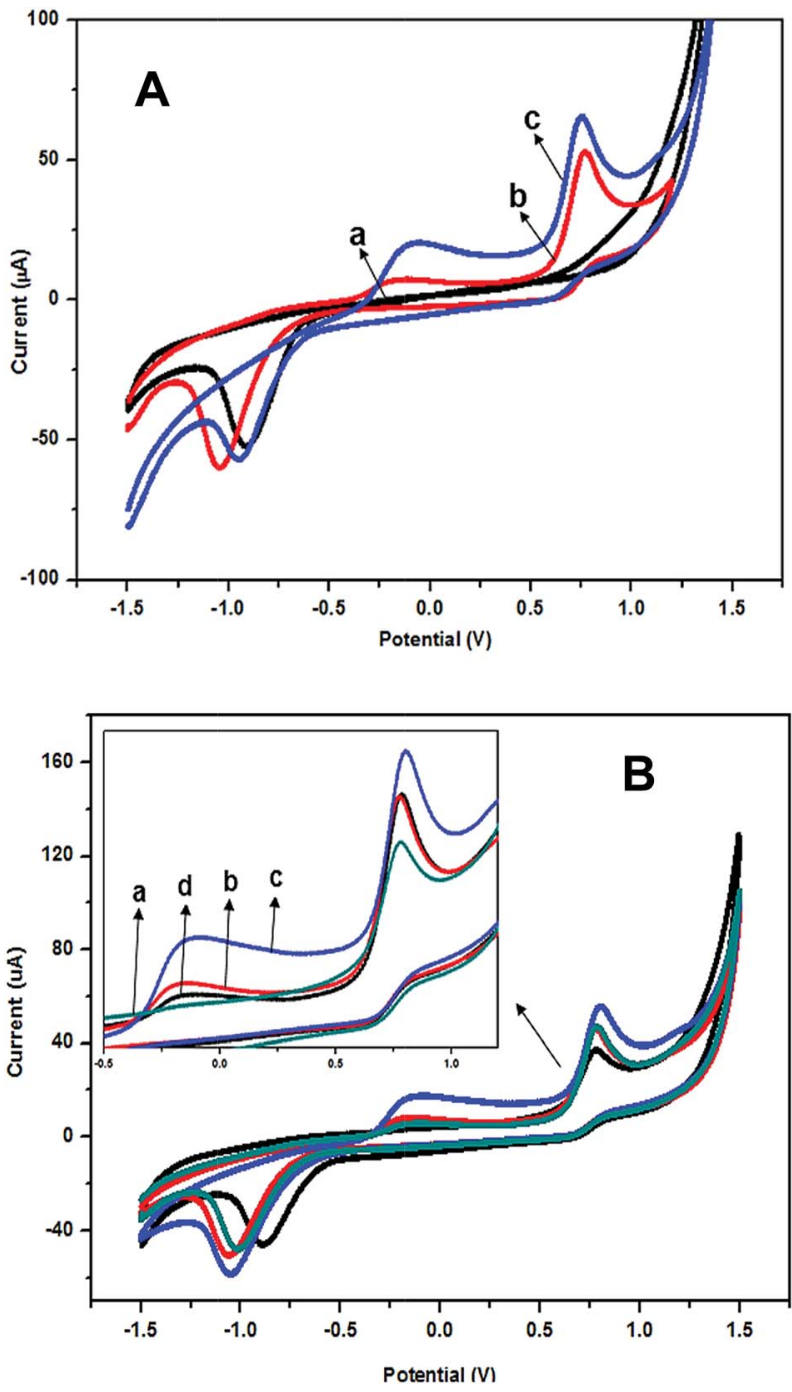

Fig. 1 (A) Cyclic voltammograms of (a) bare SPE, (b) pure PANi, and (c) PANi/CNC nanocomposite-modified electrode with a mass ratio of Ani/CNC of 0.84/0.16 and (B) cyclic voltammograms of Ani/CNC with different mass ratios where (a) $0.56 / 0.44$, (b) $0.74 / 0.26$, (c) $0.84 / 0.16$, and (d) $0.93 / 0.07$ in PBS with a pH of 7.0.

bare SPE, the modified electrodes with pure PANi, and the PANi/ CNC nanocomposite. The cyclic voltammogram of the bare SPE showed no anodic peak, whereas the PANi-modified electrode had two anodic peaks at the potentials of $-0.16 \mathrm{~V}$ and $0.76 \mathrm{~V}$. At the lower potential, only the amine form of PANi was present, indicating the presence of the leucoemeraldine form. As the potential increased, the first oxidation peak was observed at $-0.16 \mathrm{~V}$. This was associated with the conversion of the fullyreduced leucoemeraldine base to the partially-oxidized emeraldine. The second peak at $0.76 \mathrm{~V}$ occurred because of the conversion of emeraldine form to the fully oxidized pernigraniline form. ${ }^{21}$ The reduction peak at $-0.6 \mathrm{~V}$ could be due to the conversion of the electrically conductive emeraldine (EM) into the non-conducting leucoemeraldine (LEM). As was observed in other reports, ${ }^{22}$ the catalyzed oxygen reduction on the PANi surface occurred at the same potential for the formation of non-conducting leucoemeraldine (LEM). The formation of LEM increased the electrode resistance and led to a loss in the electrochemical activity of the electrode. In the presence of oxygen, much electricity was spent on its electroreduction and a reduction in the rate of formation of the nonconducting phase of LEM was observed. ${ }^{22}$

In the voltammogram of the PANi/CNC nanocompositemodified electrode, the anodic peaks drastically increased at the potentials of $-0.09 \mathrm{~V}$ and $0.76 \mathrm{~V}$ as a consequence of the PANi protonation in the presence of CNC. Another reason for this current enhancement could be related to the increase in the surface area and porosity of the nanocomposite. The incorporation of CNC inside the composite produced nanostructures with a high surface area and porosity that facilitated electron transfer and improved the electrochemical properties of the nanocomposite-modified electrode.

Fig. 1B presents the voltammogram of the nanocompositemodified electrodes with different mass ratios of aniline and CNC. Herein, on increasing the CNC content from 7 to 16 percent (mass ratio of Ani/CNC from 0.93/0.07 to $0.84 / 0.16$ ) in the nanocomposite, the oxidation peaks at the potentials of $-0.16 \mathrm{~V}$ and $0.78 \mathrm{~V}$ increased and showed a higher current response in both the anodic and cathodic peaks. This was possibly due to the higher protonation of PANi in the presence of a higher amount of CNC. Subsequently, when the CNC content increased and the PANi content decreased, the cyclic voltammogram of PANi/CNC had a lower anodic peak and the nanocomposite of PANi/CNC with a mass ratio of $0.56 / 0.44$ had the lowest redox current. This was probably due to the insulating nature of cellulose that restricted the electron transfer in the polymer chain.

Fig. 2 presents the $\mathrm{CV}$ curves for the PANi/CNC-modified electrode at various scan rates ranging from 10 to $100 \mathrm{mV} \mathrm{s}^{-1}$. Both the oxidation and reduction peaks increased with the increasing scan rate. The scan rate affects the concentration profile around the electrode, which can change the rate of charge transport. This phenomenon shows the diffusioncontrolled process of a system. As presented in Fig. 2, most of the $\mathrm{CV}$ cycles showed both the oxidation and reduction peaks, in which the anodic potential shifted towards the lower potential and the cathodic potential slightly shifted to the more negative value as the scan rate increased. The anodic and cathodic peak currents were found to be proportional to the square root of the scan rate and the peak current, as shown in the inset of Fig. 2, which clearly indicated the occurrence of a diffusion-controlled process. ${ }^{23}$

EIS analysis was carried out to investigate the electrochemical behavior of all the electrode/electrolyte systems of the polymer-modified SPE. The electron transfer between the analytes and the electrode surface (substrate) is a fundamental phenomenon in biosensors, which is caused by the rapid redox reaction of the enzyme and analyte on the electrode surface. As is known, higher electron transfer will increase the sensitivity of the target sensor. The Nyquist plots of the bare SPE, pure PANi, and PANi/CNC-modified electrodes are presented in Fig. 3A. As can be seen, the impedance characteristic of the electrodes was governed by the charge transfer resistance $\left(R_{\mathrm{ct}}\right)$, solution 


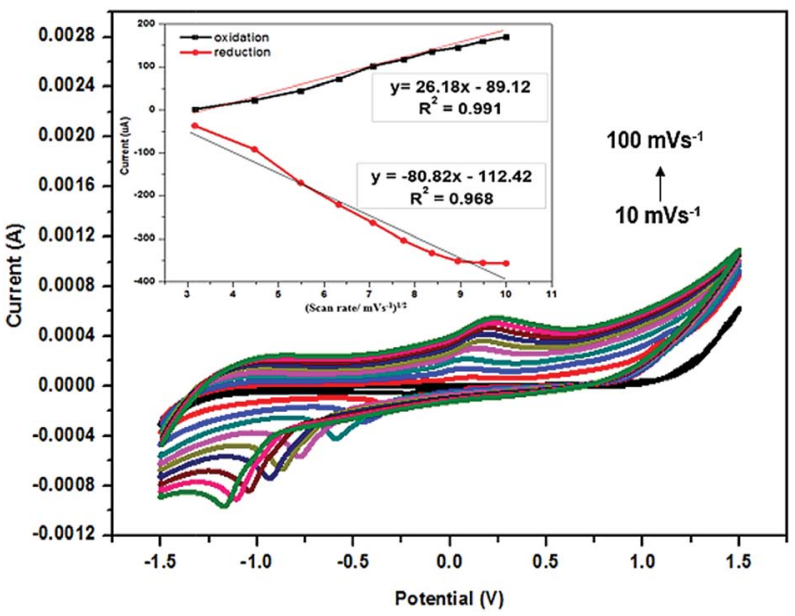

Fig. 2 Cyclic voltammograms of a PANi/CNC-modified electrode with different scan rates ranging from 10 to $100 \mathrm{mV} \mathrm{s}^{-1}$ in PBS with $\mathrm{pH}$ 7. Inset: plot of oxidation and reduction peak current against square root of scan rate.

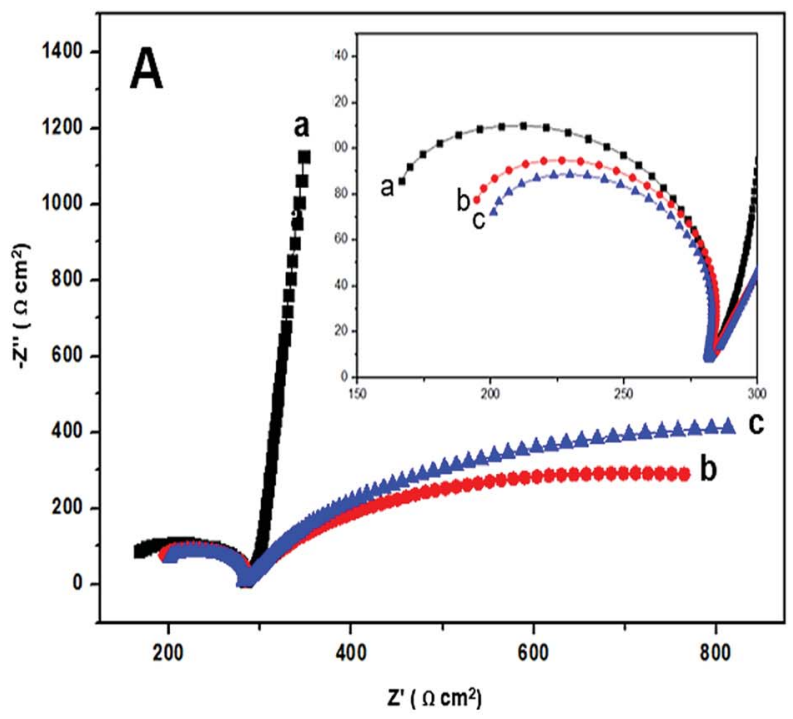

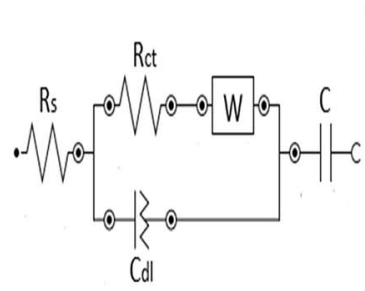

(a)

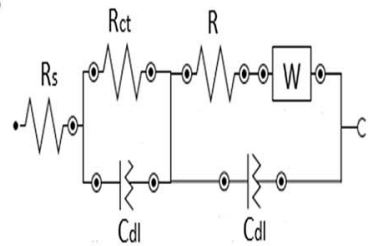

(b)
Fig. 3 (A) Nyquist plots of (a) bare SPE, (b) pure PANi, and (c) PANi/ CNC-modified electrodes in PBS with $\mathrm{pH}$ 7. Inset shows the semicircle of the Nyquist plot. (B) Randles equivalent circuit model of (a) bare SPE and (b) pure PANi and PANi/CNC-modified electrode.

resistance $\left(R_{\mathrm{s}}\right)$, double layer capacitance $\left(C_{\mathrm{dl}}\right)$, and Warburg impedance $(W)$. The charge transfer resistance $\left(R_{\mathrm{ct}}\right)$ is a measure of the rate of electron transfer between the redox species and the electrode during the electrochemical reaction course, whereas the solution resistance $\left(R_{\mathrm{s}}\right)$ represents the solutionphase interference that primarily arises from the electrolyte resistance. ${ }^{24}$ Warburg impedance $(W)$ associated with the impedance of the diffusive ion transportation and $C_{\mathrm{dl}}$ represents a double layer capacitance. ${ }^{25}$

The bare SPE plot showed a large semicircle in the low frequency region and a straight line close to an angle of $90^{\circ}$ in the high frequency region with an $R_{\mathrm{ct}}$ value of $177 \Omega$. The linear line displayed an ideal behavior with a low diffusion rate of the analyte into the surface of bare SPE. This result was predictable for the bare SPE and because of this, the PANi/CNC-modified electrode was introduced to enhance the electrocatalytic properties of the electrode. The impedance plot of the PANi/CNC nanocomposite-modified electrode displayed a smaller semicircle $\left(R_{\mathrm{ct}}: 148 \Omega\right)$ compared to that of the PANi-modified electrode $\left(R_{\mathrm{ct}}: 156 \Omega\right)$, indicating higher electron transfer for the PANi/CNC-modified electrode. Although PANi is a conductive material, the irregular structure of the chemically prepared PANi might inhibit the electron transfer and the charge carrier mobility. Double layer capacitance $\left(C_{\mathrm{dl}}\right)$ exists at the interface of the electrode and electrolyte. The values of $C_{\mathrm{dl}}$ (Table 1) increased by introducing nanocellulose into the PANi structure, implying the increasing roughness and porosity of the PANi/ CNC nanocomposite, which was predictable because of the nanostructure of the composite. ${ }^{26}$

Fig. 3B exhibits the Randles equivalent circuit model used to simulate the impedance behavior of bare SPE and the modified electrodes. The value of $R_{\mathrm{ct}}$ and $C_{\mathrm{dl}}$ were determined from the Nyquist plot by fitting the semicircles with minimal error (below 1\%). PANi and PANi/CNC-modified electrode exhibited the circuit modelling result of $\mathrm{R}(\mathrm{RQ})([\mathrm{RW}] \mathrm{Q})]$ and bare SPE displayed the model of $[\mathrm{R}([\mathrm{RW}] \mathrm{Q}) \mathrm{C}]$.

\subsection{Morphology study}

The TEM and FESEM images of CNC, PANi, and PANi/CNC nanocomposite with different Ani/CNC mass ratio are presented in Fig. 4. The images of the PANi particles are shown in Fig. 4a and b. A granular structure (cluster) with micrometersized particles was observed on the surface of PANi, confirming emeraldine salt formation, in good agreement with those reported by others. ${ }^{27}$ The irregular microstructural feature was formed by the secondary growth stages of PANi during the initial growth stage of the linear chain of polymer. ${ }^{28}$ The morphology of PANi (Fig. 4b) characterized by TEM confirmed the agglomeration of polymer with no uniformity of the PANi structure.

The images of CNC presented in Fig. 4c shows an agglomerated rod-like nanocrystal structure with the diameter in the

Table 1 The $R_{\mathrm{ct}}$ and $C_{\mathrm{dl}}$ value of modified electrodes

\begin{tabular}{lll}
\hline Modified electrode & $R_{\mathrm{ct}}\left(\Omega \mathrm{cm}^{2}\right)$ & $C_{\mathrm{dl}}\left(\mathrm{mF} \mathrm{cm}^{-2}\right)$ \\
\hline Bare SPE & 177 & 125 \\
PANi & 156 & 134 \\
PANi/CNC & 148 & 151
\end{tabular}



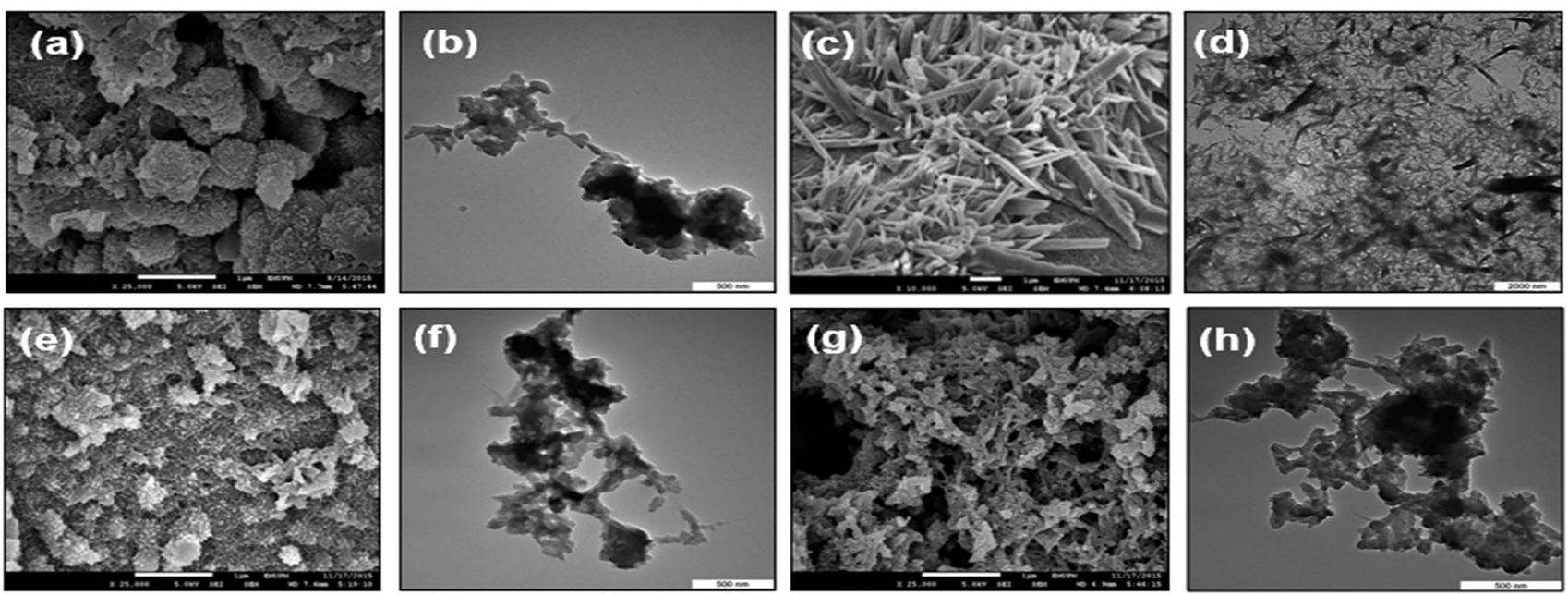

Fig. 4 FESEM and TEM images of (a-b) pure PANi, (c-d) CNC, (e-f) PANi/CNC nanocomposites with the mass ratio of Ani/CNC 0.56/0.44, and $(\mathrm{g}-\mathrm{h}) \mathrm{PANi} / \mathrm{CNC}$ nanocomposites with the mass ratio of Ani/CNC 0.93/0.07.

range of $10-20 \mathrm{~nm}$ and the length of a few micrometers. ${ }^{29}$ The nanocelluloses were well-bonded with each other, indicating the existence of strong hydrogen bonding and hydrophilic interaction between them. ${ }^{30}$ The images for the PANi/CNC nanocomposite prepared with the mass ratio of $0.56 / 0.44$ (Fig. 4e) and 0.93/0.07 (Fig. 4g) of Ani/CNC showed no phase separation, revealed a uniform polymerization of aniline on the surface of nanocellulose. Note that both nanocomposites showed fibrous structures with a high porosity nanostructure, which could be beneficial for enzyme immobilization. It was found that on increasing the amount of monomer and PANi percentage in the nanocomposite, the average diameter of the resulting particles increased. ${ }^{31}$ This might be due to the fact that for higher amount of monomer, the polymerization becomes more intensive, which results in agglomeration in some parts of the nanocomposite (Fig. $4 \mathrm{f}$ and $\mathrm{h}$ ).

\subsection{Structure and thermal study}

FT-IR spectroscopy was used to study the structural properties of the PANi/CNC nanocomposite. The FTIR spectra of the pure PANi, CNC, and PANi/CNC nanocomposite are presented in Fig. 5. Typical absorption bands of pure PANi were observed at $1651 \mathrm{~cm}^{-1}, 1534 \mathrm{~cm}^{-1}, 1400 \mathrm{~cm}^{-1}, 1246 \mathrm{~cm}^{-1}$, and $700 \mathrm{~cm}^{-1}$. The characteristic peak at $3350 \mathrm{~cm}^{-1}$ corresponds to the $\mathrm{N}-\mathrm{H}$ stretchings. ${ }^{32}$ The broad band at $3200 \mathrm{~cm}^{-1}$ corresponds to the overlap of $\mathrm{C}-\mathrm{H}$ stretching, the deformation of the benzenoid structure, and the stretching vibration of the $\mathrm{N}-\mathrm{H}$ bonds. This broad band clearly revealed the emeraldine base form of PANi. ${ }^{1}$ The characteristic peaks at $2938 \mathrm{~cm}^{-1}$ and $1651 \mathrm{~cm}^{-1}$ are associated with the $\mathrm{C}-\mathrm{H}$ and $\mathrm{C}=\mathrm{C}$ stretching in the polyaniline units, respectively. The peaks at $1534 \mathrm{~cm}^{-1}$ and $1400 \mathrm{~cm}^{-1}$ are associated with the aromatic ring stretching of the $\mathrm{C}=\mathrm{C}-\mathrm{C}$ bonds. These peaks that are referred as the stretching vibrations of $\mathrm{N}-\mathrm{B}-\mathrm{N}$ and $\mathrm{N}=\mathrm{Q}=\mathrm{N}(\mathrm{B}=$ benzoid, $\mathrm{Q}=$ quinoid $)$ are in good agreement with those reported in literature. ${ }^{1,2}$ The peaks at 1246 $\mathrm{cm}^{-1}$ are associated with the $\mathrm{C}-\mathrm{N}$ stretching vibration mode of the $\mathrm{N}-\mathrm{Ph}-\mathrm{N}$ unit, and the peak at $700 \mathrm{~cm}^{-1}$ corresponds to $\mathrm{NH}_{2}$ wagging. ${ }^{33,34}$

The nanocellulose prepared from the Semantan bamboo showed characteristic peaks at $3331 \mathrm{~cm}^{-1}$ and $2893 \mathrm{~cm}^{-1}$ that corresponded to the stretching of the hydroxyl group (in the presence of H-bonds) and stretching vibration of $\mathrm{C}-\mathrm{H}$ in the pyranoid ring, respectively. ${ }^{16}$ The band at $1642 \mathrm{~cm}^{-1}$ resulted from the $\mathrm{H}-\mathrm{O}-\mathrm{H}$ bending of the absorbed water. ${ }^{35}$ The characteristic peaks appearing at $3331 \mathrm{~cm}^{-1}, 2893 \mathrm{~cm}^{-1}$, and $1642 \mathrm{~cm}^{-1}$ were in good agreement with those reported by Liu et al. They prepared nanocellulose from flax yarn by the acid hydrolysis method. Peaks at $1431 \mathrm{~cm}^{-1}, 1321 \mathrm{~cm}^{-1}, 1156 \mathrm{~cm}^{-1}$, and 1029 $\mathrm{cm}^{-1}$ correspond to the - $\mathrm{OCH}$ in-plane bending, $\mathrm{C}-\mathrm{H}$ deformation, $\mathrm{C}=\mathrm{C}$ stretching, and $\mathrm{C}-\mathrm{O}-\mathrm{C}$ stretching, respectively. ${ }^{36}$

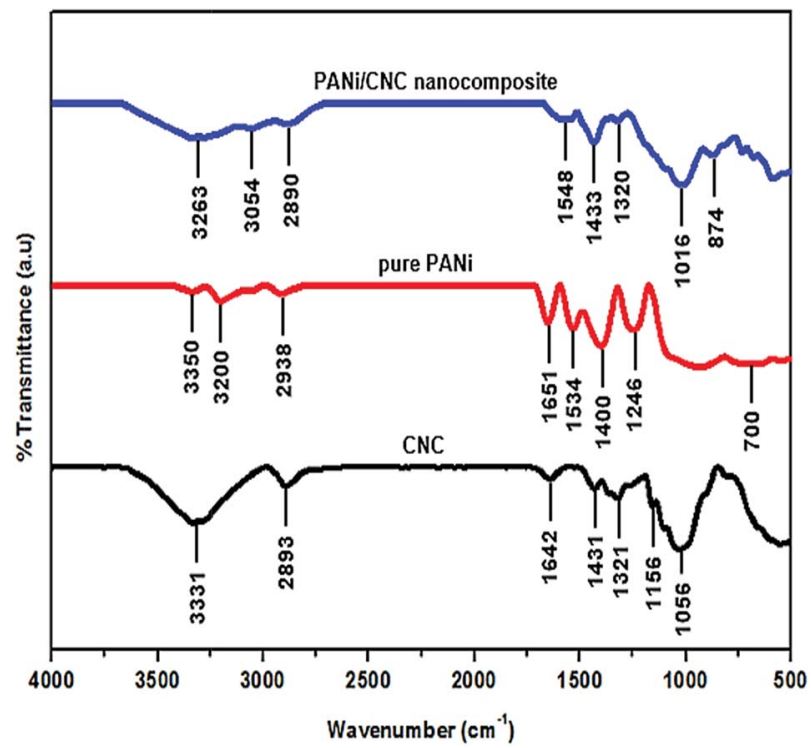

Fig. 5 FT-IR spectra of PANi/CNC nanocomposite, pure PANi, and CNC. 
The PANi/CNC nanocomposite revealed overlapped adsorption bands of pure PANi and nanocellulose in the infrared spectra, demonstrating the polymerization of aniline on the surface of nanocrystal cellulose. Compared to the pure materials CNC and PANi, the characteristic peaks of the nanocomposite showed lower intensity, which could be due to the coverage of the nanocellulose surface with the polyaniline layer. ${ }^{34}$ Overlapping characteristic peaks of pure PANi at $3200 \mathrm{~cm}^{-1}$ and the CNC peak at $3331 \mathrm{~cm}^{-1}$ formed a broad band at $3263 \mathrm{~cm}^{-1}$ in the nanocomposite spectra. The peak of hydroxyl stretching of CNC that shifted to a higher wavenumber of $3337 \mathrm{~cm}^{-1}$ in the PANi/ CNC nanocomposite could possibly be due to the interaction of the $\mathrm{O}-\mathrm{H}$ group in cellulose and the amine group in aniline. ${ }^{34}$ The stretching vibration of the benzoid form of PANi appearing at $1548 \mathrm{~cm}^{-1}$ in the PANi/CNC nanocomposite showed a uniform formation of PANi on the nanofibrous structure.

Fig. 6 compares the XRD diffractogram of pure PANi, CNC, and the PANi/CNC nanocomposite. The diffractogram of pure PANi showed peaks at $2 \theta=20.5^{\circ}$ and $25.4^{\circ}$, corresponding to the (020) and (200) crystal planes, respectively, confirmed that polyaniline was in the form of emeraldine salt. ${ }^{37}$ The crystallinity of PANi can be ascribed to the repetition of the benzoid and quinoid rings in the PANi chains. ${ }^{38}$ The highest peak appeared at $2 \theta=25.4^{\circ}$ and revealed the semi-crystalline structure of PANi that was attributed to the periodic array perpendicular to the polymer chain, and the peak at $2 \theta=20.5^{\circ}$ was related to the periodic arrays parallel to the polymer chain. ${ }^{39}$ The CNC diffractogram displayed well-defined primary peaks ranging from $22^{\circ}$ to $23^{\circ}$, indicating a highly crystalline structure. $^{40}$ In our study, the diffractogram of nanocellulose, prepared from bamboo, displayed peaks at $2 \theta=16.1^{\circ}, 22.5^{\circ}$, and $34.4^{\circ}$, corresponding to the (110), (200), and (004), crystallographic planes, respectively, describing cellulose type $\mathrm{I}^{\mathbf{3 0 , 4 1}}$ The nanocellulose prepared from green seaweed by the acid hydrolysis method presented XRD patterns almost similar to those reported in our study. ${ }^{41}$

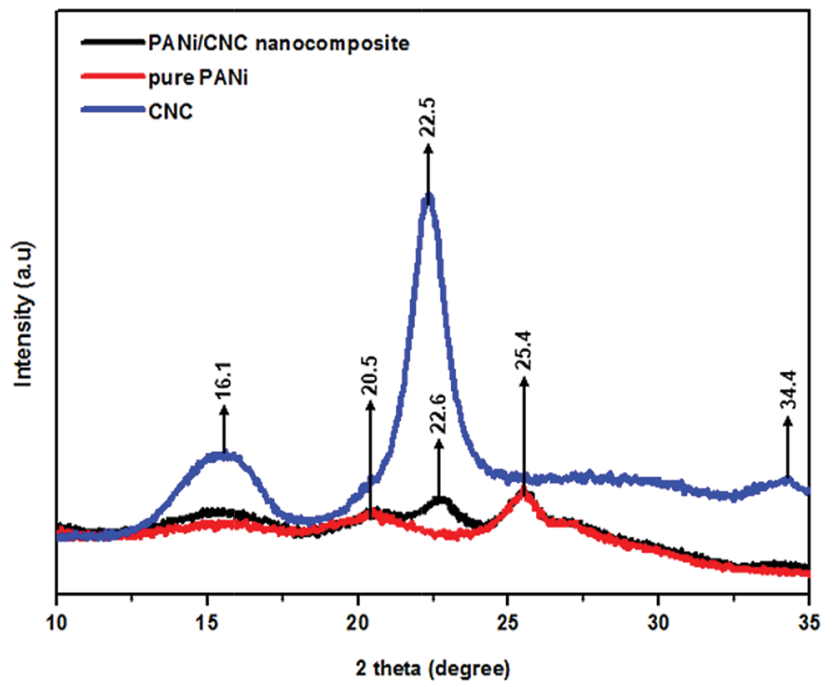

Fig. 6 X-ray diffractogram of $\mathrm{CNC}$, pure $\mathrm{PANi}$, and $\mathrm{PANi} / \mathrm{CNC}$ nanocomposite.
The XRD diffractogram of the PANi/CNC nanocomposite prepared from Ani/CNC with a mass ratio of 0.84/0.16 showed the coexistence of characteristic peaks of PANi and CNC at $16.1^{\circ}, 20.5^{\circ}, 22.6^{\circ}$, and $25.4^{\circ}$, demonstrating the formation of PANi on the surface of crystalline cellulose. However, the intensity of the peaks and the crystallinity of nanocellulose at 2 theta $=22.6^{\circ}$ decreased with the addition of PANi in the nanocomposite..$^{42}$ The crystallinity of the nanocomposite can be enhanced by increasing the CNC content inside the nanocomposite. ${ }^{43}$ From the XRD data, the crystallinity index (CI) was calculated according to the formula developed by Segal et al. ${ }^{\mathbf{4 4 , 4 5}}$ The formula is as follows:

$$
\mathrm{CI}=\frac{\left(I_{200}\right)\left(I_{\mathrm{Am}}\right)}{\left(I_{200}\right)}
$$

where $I_{200}$ is the crystalline peak value (at 22.5 ${ }^{\circ}$ ) and $I_{\mathrm{Am}}$ is the amorphous peak value. The CI of CNC and PANi/CNC nanocomposite were calculated as $78.34 \%$ and $27.98 \%$, respectively. As can be seen, the CI data confirmed that the addition of PANi in the nanocomposite reduced the crystallinity of the resulting polymer.

Fig. 7 shows the TG curves of pure PANi, CNC, and the PANi/ CNC nanocomposite. The PANi/CNC nanocomposite sample was prepared from a solution containing Ani and CNC with a mass ratio of $0.84 / 0.16$. Pure PANi powder externally doped using $\mathrm{HCl}$ and persulfate ion experienced three major weight losses starting with the removal of moisture that occurred around $56{ }^{\circ} \mathrm{C}$ to $149^{\circ} \mathrm{C}$. The second weight loss, which was due to dopant decomposition, gradually occurred from $150{ }^{\circ} \mathrm{C}$ to $450{ }^{\circ} \mathrm{C}$. Lastly, the third stage occurred around $460{ }^{\circ} \mathrm{C}$ to $670{ }^{\circ} \mathrm{C}$ and is attributed to the decomposition of the polymer backbone. The thermal decomposition pattern of pure PANi is in agreement with that reported in other studies. ${ }^{\mathbf{4 6 , 4 7}}$

The TG curve of CNC shows a two-step thermal decomposition starting from $75{ }^{\circ} \mathrm{C}$ to $150{ }^{\circ} \mathrm{C}$, which corresponds to the moisture removal of the absorbed and intermolecular $\mathrm{H}$ bonded water. ${ }^{30}$ The second degradation from 160 to $350{ }^{\circ} \mathrm{C}$ is

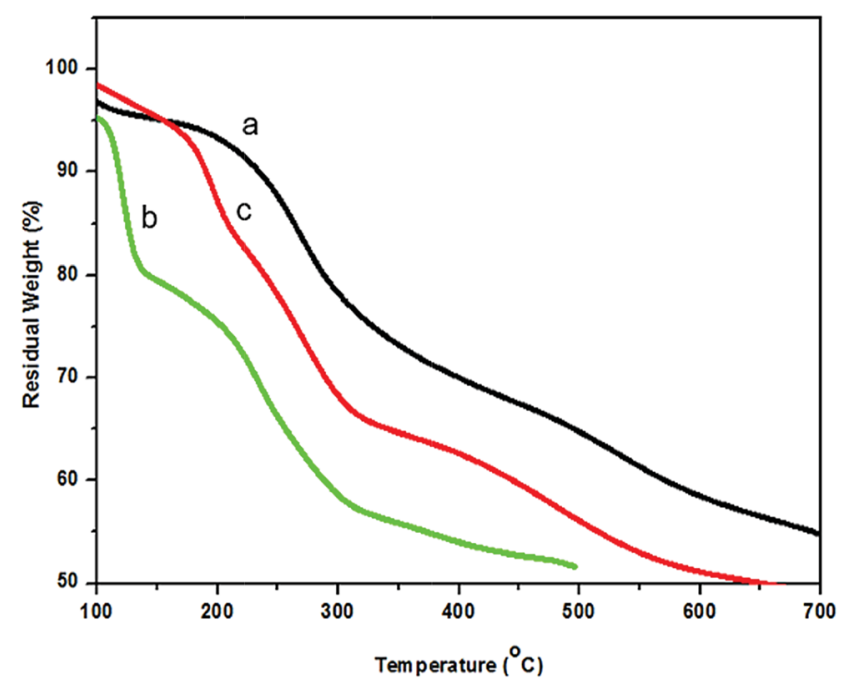

Fig. 7 TG curve of (a) pure PANi, (b) CNC, and (c) PANi/CNC nanocomposite. 
attributed to the polymer chain scission, cross-link formation, and cross-link breakage. The low thermal stability was predictable for nanocellulose because of the fact that during the acid hydrolysis process, sulfate groups $\left(\mathrm{O}-\mathrm{SO}_{3} \mathrm{H}\right)$ from sulfuric acid substituted the hydroxyl groups, leading to lower activation energy and catalyzing the nanocellulose decomposition. ${ }^{48}$

The TG curve of PANi/CNC showed three degradation steps. The first step occurred from $61{ }^{\circ} \mathrm{C}$ to $200{ }^{\circ} \mathrm{C}$ and contributed to the evaporation of water from the composite. Note that the first degradation of the PANi/CNC nanocomposite happened at higher temperature compared to that of pure PANi. The incorporation of crystalline nanocellulose into PANi increased the crystalline structure of PANi, where more energy was required to remove water/acid from the polymer chain. ${ }^{49}$ The second weight loss stage was attributed to the pyrolysis of cellulose that was observed over the range from $230{ }^{\circ} \mathrm{C}$ to $350{ }^{\circ} \mathrm{C}$. ${ }^{1}$ The thermal decomposition of the cellulose content in the PANi/CNC nanocomposite occurred at higher temperature compared to that of pure $\mathrm{CNC}$, indicating the protection of PANi that covered the surface of nanocellulose. ${ }^{16}$

The final weight loss of the PANi/CNC nanocomposite was observed from $367{ }^{\circ} \mathrm{C}$ to $642{ }^{\circ} \mathrm{C}$, corresponding to the thermal decomposition of the PANi backbone. A lower maximum decomposition temperature was observed for the PANi/CNC nanocomposite compared to that for pure PANi $\left(665^{\circ} \mathrm{C}\right)$, confirming the interactions between the two constituents of the composite. A similar pattern of thermal degradation of the PANi/cellulose composite has been reported by Casado et al. ${ }^{1}$ In summary, the thermal stability of cellulose was noticeably increased by incorporating PANi. ${ }^{50}$

\section{Conclusions}

The synergistic effect of CNC and conducting polymers on the electrochemical properties along with high porosity of nanocomposite has made this material a good candidate for hosting enzymes and biomolecules. The conductive biocompatible nanocellulose-based composites are promising for use in sensors, batteries, and conductive adhesives. The polyaniline nanocomposite showed an X-ray diffraction pattern consisting of four peaks at $16^{\circ}, 20^{\circ}, 22^{\circ}$, and $25^{\circ}$, which indicated the presence of the emeraldine salt of polyaniline and incorporation of nanocellulose in the nanocomposite. Nanocomposites with highest aniline content showed lower thermal stability compared to pure aniline. EIS data confirmed a higher electron transfer for the PANi/CNCmodified electrode with smaller semicircle and $R_{\mathrm{ct}}$ value.

\section{Acknowledgements}

The authors would like to acknowledge the Ministry of Science, Technology and Innovation (MOSTI), and Universiti Putra Malaysia (UPM) for funding this project under research grants, Science Fund 5450776 (Project No: 02-01-04-SF1983).

\section{References}

1 U. M. Casado, M. I. Aranguren and N. E. Marcovich, Ultrason. Sonochem., 2014, 21, 1641-1648.
2 N. D. Luong, J. T. Korhonen, A. J. Soininen, J. Ruokolainen, L. S. Johansson and J. Seppälä, Eur. Polym. J., 2013, 49, 335-344.

3 M. Hwang, J. Oh, J. Kang, K. Dong Seong and Y. Piao, Electrochim. Acta, 2016, 221, 23-30.

4 M. Faraji, P. Najafi Moghadam and R. Hasanzadeh, Chem. Eng. J., 2016, 304, 841-851.

5 F. Ye, B. Zhao, R. Ran and Z. Shao, J. Power Sources, 2015, 290, 61-70.

6 X. Li, M. Yu, Z. Chen, X. Lin and Q. Wu, Sens. Actuators, B, 2017, 239, 874-882.

7 G. Zhu, Q. Zhang, G. Xie, Y. Su, K. Zhao, H. Du and Y. Jiang, Chem. Phys. Lett., 2016, 665, 147-152.

8 Y. Luan, J.-S. Noh and S. H. Kim, Mater. Chem. Phys., 2017, 190, 68-73.

9 M. A. Soto-Oviedo, O. A. Araújo, R. Faez, M. C. Rezende and M. A. De Paoli, Synth. Met., 2006, 156, 1249-1255.

10 S. Bhadra, D. Khastgir, N. K. Singha and J. H. Lee, Prog. Polym. Sci., 2009, 34, 783-810.

11 M. S. Cho, S. Y. Park, J. Y. Hwang and H. J. Choi, Mater. Sci. Eng., C, 2004, 24, 15-18.

12 P. Xiong, C. Hu, Y. Fan, W. Zhang, J. Zhu and X. Wang, J. Power Sources, 2014, 266, 384-392.

13 J. Qi, X. Xu, X. Liu and K. T. Lau, Sens. Actuators, B, 2014, 202, 732-740.

14 D. Y. Liu, G. X. Sui and D. Bhattacharyya, Compos. Sci. Technol., 2014, 99, 31-36.

15 G. Nystrom, A. Razaq, M. Strømme, L. Nyholm and A. Mihranyan, Nano Lett., 2009, 9, 3635-3639.

16 Z. Mo, Z. Zhao, H. Chen, G. Niu and H. Shi, Carbohydr. Polym., 2009, 75, 660-664.

17 B. L. Peng, N. Dhar, H. L. Liu and K. C. Tam, Can. J. Chem. Eng., 2011, 89, 1191-1206.

18 L. Brinchi, F. Cotana, E. Fortunati and J. M. Kenny, Carbohydr. Polym., 2013, 94, 154-169.

19 R. J. Moon, A. Martini, J. Nairn, J. Simonsen and J. Youngblood, Cellulose nanomaterials review: structure, properties and nanocomposites, 2011, vol. 40.

20 S. Ghosh, B. Vishalakshi and V. Kalpagam, Synth. Met., 1992, 46, 349-352.

21 Y. J. Shin and J. Kameoka, J. Ind. Eng. Chem., 2012, 18, 193197.

22 New Carbon Based Materials for Electrochemical Energy Storage Systems: Batteries, Supercapacitors and Fuel Cells, ed. I. V Barsukov, C. S. Johnson, J. E. Doninger and V. Z. Barsukov, 2006.

23 S. Nandini, S. Nalini, M. B. M. Reddy, G. S. Suresh, J. S. Melo, P. Niranjana, J. Sanetuntikul and S. Shanmugam, Bioelectrochemistry, 2016, 110, 79-90.

24 I. I. Suni, TrAC, Trends Anal. Chem., 2008, 27, 604-611.

25 M. H. Mat Zaid, J. Abdullah, N. A. Yusof, Y. Sulaiman, H. Wasoh, M. F. Md Noh and R. Issa, Sens. Actuators, B, 2016, 241, 1024-1034.

26 L. Škantárová, R. Oriňaková, A. S. Fedorková, P. Bača, M. Sedlaříková and A. Oriňak, Int. J. Electrochem. Sci., 2015, 10, 8569-8580. 
27 U. M. Casado, R. M. Quintanilla, M. I. Aranguren and N. E. Marcovich, Synth. Met., 2012, 162, 1654-1664.

28 A. Abdolahi, E. Hamzah, Z. Ibrahim and S. Hashim, Materials, 2012, 5, 1487-1494.

29 X. Wu, C. Lu, H. Xu, X. Zhang and Z. Zhou, ACS Appl. Mater. Interfaces, 2014, 6, 21078-21085.

30 A. Kumar, Y. S. Negi, V. Choudhary and N. K. Bhardwaj, J. Mater. Phys. Chem., 2014, 2, 1-8.

31 V. P. Anju and S. K. Narayanankutty, AIP Adv., 2016, 6, 015109.

32 R. Borah, S. Banerjee and A. Kumar, Synth. Met., 2014, 197, 225-232.

33 M. H. Lissarrague, M. E. Lamanna, N. B. D'Accorso and S. Goyanes, Synth. Met., 2012, 162, 1052-1058.

34 Y. Zhou, Q. Song, B. Liang and Z. Qin, Int. Conf. Adv. Energy, Environ. Chem. Eng., 2015, 797-800.

35 J. I. Morán, V. A. Alvarez, V. P. Cyras and A. Vázquez, Cellulose, 2008, 15, 149-159.

36 S. Y. Oh, D. Il Yoo, Y. Shin and G. Seo, Carbohydr. Res., 2005, 340, 417-428.

37 S. B. Kondawar, M. D. Deshpande and S. P. Agrawal, Int. J. Compos. Mater., 2012, 2, 32-36.

38 M. Ayad, G. El-Hefnawy and S. Zaghlol, Chem. Eng. J., 2013, 217, 460-465.
39 B. Kavitha, K. Siva Kumar and N. Narsimlu, Indian J. Pure Appl. Phys., 2013, 51, 207-209.

40 M. Karim, Z. Chowdhury, S. Hamid and M. Ali, Materials, 2014, 7, 6982-6999.

41 M. Rathod, S. Haldar and S. Basha, Ecological Engineering, 2015, 84, 240-249.

42 D. Zhang, L. Zhang, B. Wang and G. Piao, J. Mater. Chem. A, 2013, 2013, 614507.

43 A. Alemdar and M. Sain, Bioresour. Technol., 2008, 99, 16641671.

44 S. Park, J. O. Baker, M. E. Himmel, P. A. Parilla and D. K. Johnson, Biotechnol. Biofuels, 2010, 3, 10.

45 L. Segal, L. Creely, A. E. Martin and C. M. Conrad, Text. Res. J., 1959, 29, 786-794.

46 P. Bhattacharya, S. Dhibar, G. Hatui, A. Mandal, T. Das and C. K. Das, RSC Adv., 2014, 4, 17039-17053.

47 M. Joelma, R. Cardoso, M. Fogliato, S. Lima and D. M. Lenz, Mater. Res., 2007, 10, 425-429.

48 F. Kallel, F. Bettaieb, R. Khiari, A. García, J. Bras and S. E. Chaabouni, Ind. Crops Prod., 2016, 87, 287-296.

49 X. Zhang, J. Zhu, N. Haldolaarachchige, J. Ryu, D. P. Young, S. Wei and Z. Guo, Polymer, 2012, 53, 2109-2120.

50 S. K. Shukla, Indian J. Eng. Mater. Sci., 2012, 19, 417-420. 